\title{
Disability and bodies as bearers of value
}

\author{
by
}

\author{
Claire Edwards \\ Research and Evaluation Unit \\ Disability Rights Commission \\ 222 Grays Inn Road \\ London \\ WC1X 8HL \\ claire.edwards@drc-gb.org
}

and

\author{
Rob Imrie \\ Department of Geography \\ Royal Holloway University of London \\ Egham \\ Surrey \\ TW20 0EX \\ r.imrie@ rhul.ac.uk
}




\begin{abstract}
This paper considers the relevance of Pierre Bourdieu's conceptions of the body to the development of disability theory. We begin by discussing the limitations of reductive conceptions of disability. In so doing, we consider how far Bourdieu's (1990) concept of habitus offers a way of bringing an analysis of the body to bear upon an understanding of the social inequalities which are core to the lives of disabled people. Through focus groups with disabled people, the paper explores aspects of disabled people's corporeal identities, feelings, and (embodied) encounters in a range of social settings. The research shows that disabled people's lives are connected to different 'valuations' attributed to corporeal forms, and to systems of signification and representation which underpin them. We conclude by reaffirming the need to consider Bourdieu's ideas in helping in the development of disability theory.
\end{abstract}




\section{(1). Introduction}

"The whims of architecture have enormous power over my experience of vision: a postmodern shopping mall with its cantilevered floors and mirrored walls - all lit by indirect lighting and high intensity bulbs - can reduce my momentum. The darkness of restaurants and bars tightens my chest. I edge along without poise, feeling the sudden reverberations of alarm that come with not seeing...How does one become inured to unpredictable moments of helplessness?" (Kuusisto, 1998: 11-12).

Kuusisto's testimony is familiar to many people with physical and mental impairments whose bodily functions are influenced, and often compromised, by broader social and structural relations. Paterson and Hughes (1999), for instance, document how people with speech impediments are often ignored and made to feel inferior because of their inability to communicate according to societallydefined norms of accepted speech standards and behaviour. Likewise, Hawkesworth (2001) refers to people with facial scarring who feel too ashamed to enter public places without the daily ritual of covering up the face with cosmetics. Others consider the stigmatising of disabled people, or the cultural encoding of disabled bodies as diseased, inferior, and lacking mental capacities and capabilities (Barnes, et al, 1999). In all these instances, individual bodies intermingle with broader socio-cultural relations to produce what Grosz (1994: 19) refers to as sites 'of contestation in a series of economic, political, sexual and intellectual struggles'.

However, an understanding of the interrelationships between disabled people's bodily functions, and broader socio-cultural values and practices, is underdeveloped in disability studies. Whilst literature on gender has been engaging with post-structuralist ideas about the body and its social construction for some years, disability theory has tended to revolve around the dichotomy of 
the medical and social models of disability. Whereas the former relies on a naturalistic conception of disability, that biology is at the root of impairment which, in turn, causes disability, the former defines disability as a social construction through which society oppresses disabled people. Both conceptions, while capturing aspects of disabled people's lives, are problematical for failing to recognise that there is a dialectical relationship between the individual and society, or where intersubjective and subjective experiences are entwined.

In moving beyond reductive conceptions of disability, Barnes, et al (1999: 210) call for 'the application of the sociological imagination to the field of disability' which 'directs attention to exploring the links between structural conditions and people's lived experience of the process of disablement'. Others suggest that the analysis of the body should be the meeting place for sociological and disability theory (Hughes, 1999, Shilling, 1993). Such calls, for an embodied notion of disability, are characterised by a bewildering range of approaches, ranging from the study of the 'body as text', to the body as the site at which power/knowledge is realised. For Merleau-Ponty (1962), the body is an active creator of significance and the site of meaningful expression or, as Marks (1999: 129) suggests, 'the body should not be seen as matter set apart from subjectivity and the environment, but as an entity inextricably bound up with creative meaning and context'.

A response to such observations is to deploy Bourdieu's conception of the body as a bearer of value in society, or as 'a possessor of power, status and distinctive symbolic forms integral to the accumulation of various resources' (Shilling, 1993: 124). For Bourdieu, the body and its social location are interrelated, while the management of the body is core to the acquisition of status and distinction. As Bourdieu $(1977,1990)$ comments, the body can be understood in and through the 
habitus or what Jenkins (1992: 74) refers to as 'habit or typical conditions or appearance, particularly of the body'. Thus, ways of talking, of moving, bodily deportment, and general demeanour are integral to habitus or, as Marks (1999: 129) notes, 'the body adopts a particular habitual way of relating to the environment'. Habitus, then, seeks to focus on the corporeal, embodied, experiences of everyday life and to understand systems of interaction between individual social beings and broader social structures in the (re) production of social inequalities.

In discussing the relevance of aspects of Bourdieu's ideas to the development of disability theory, we divide the paper into three (1). First, we discuss the limitations of reductive conceptions of disability, and consider how far Bourdieu's (1990) concept of habitus offers a way of bringing an analysis of the body to bear upon an understanding of the social inequalities which are core to the lives of disabled people. Second, through focus groups with disabled people, we explore aspects of disabled people's corporeal identities, feelings, and (embodied) encounters in a range of social settings. The illustrative material shows that disabled people's lives are intimately connected to different 'valuations' of corporeal forms, and to systems of signification and representation which underpin them. We conclude by reaffirming the need to consider Bourdieu's ideas in helping in the development of disability theory.

\section{(2). Corporeality and reductive conceptions of impairment and disability.}

A range of authors note that the development of sociological conceptions of disablement is not well served by either medical or social models of disability (Barnes, et al, 1999, Hughes, 1999). The medical model is primarily concerned with 
an analysis of the physical body, or propagating a medical orthodoxy which conceives of bodies as objects to be cared for through the application of medicine and rehabilitative techniques. Such ideas are connected to the reductive understanding that 'the capabilities and limitations of the body determine the state and development of society and social relations' (Hall, 1999: 143). Oliver (1996), however, has attacked the medical profession for the way it ignores the social and personal concerns of disabled people in favour of a 'physicalist' approach. The medical concept isolates the disabled person as a consequence of their impairment and refuses to recognise how social attitudes to disability are formative to a disabled person's identity.

In contrast, the social model seeks to understand disability as a socially generated category and related series of experiences external to the body. Thus, disability is the body being transformed by 'living in society', or where a person with an impairment is disabled through the attitudes and norms by which society defines them. For some, such as Douglas (1966), the (disabled) body is a receptor of social meanings while, for others, it is but a non-biological reflection of social processes (Shilling, 1993). In general, however, social conceptions of disability largely discount the corporeal, fleshy, body or, as Morris (1991: 10) notes, there is a denial of 'the personal experience of physical and mental restrictions, of illness, of the fear of dying'. Likewise, Meekosha (1998: 175) comments on how the social model leaves 'the impaired body as untouched, unchallenged: a taken-for-granted fixed corporeality', or, as Shilling (1993: 10) suggests, social constructivist models, at best, conceive of the body only insofar as 'the body is named as a theoretical space, but often remains neglected as an actual object of analysis'. 
In seeking to transcend the division and differences between the medical and the social, or the body as nature or culture, the notion of embodiment has become relevant (2). For Turner (1992), embodiment is an understanding of the body as biological or corporeal and as, simultaneously, entwined with society. As Hall (1999: 144) suggests, 'the body...is neither determined by biology nor society, but absorbs and reacts to biological and social processes in a never-ending process'. Grosz (1994: 19) also comments that the body should be seen as a 'site of contestation' or reactive to social processes. She points the way to re-figuring the relationship between the biological and societal by suggesting that 'the openness of organic processes to cultural intervention, transformation or even production, must be explored' (Grosz, 1994: 23). Others concur with Elias (1991) arguing that our capacity for language and consciousness are contained within, and are limited by, our bodies. Likewise, Shilling (1993: 9) suggests that any theory of human agency or action requires an account of the body, that 'acting people are acting bodies'.

Such ideas resonate with Bourdieu's $(1977,1985,1990)$ theory of practice which denies that social practices are either to be understood in terms of objective social laws or the result of 'the independent subjective decision making of free human beings' (Painter, 2000: 242). Rather, practice revolves around the habitus or the ways in which the body develops habitual ways of relating to broader sociopolitical environments and relations. As Painter (2000: 242) suggests, the habitus is 'the mediating link between objective social structures and individual action and refers to the embodiment in individual actors of systems of social norms, understandings and patterns of behaviour'. In turn, the forms of embodiment are likely to dispose actors to behave in particular ways. In elaborating, Bourdieu (1990: 126) notes: 
'to speak of habitus is to assert that the individual, and even the personal, the subjective, is social, collective. Habitus is a socialised subjectivity...neither the individual...nor groups as concrete sets of individuals sharing a similar location in social space, but in relation between two realisations of historical action, in bodies and things'.

For Bourdieu, there is a distinction between rules and practices. Whilst objectives rules and norms may be established by institutions, they do not translate directly into people's actions. Rather they take on practical form in the habitus. Rejecting positivistic conceptions of a world 'out there', Bourdieu (1990: 52) suggests that 'objects of knowledge are constructed...and...the principle of this construction is the system of structured, structuring practices and dispositions, the habitus'. The habitus is thus defined as 'systems of durable, transposable dispositions' (Bourdieu, 1990: 53), or 'the basic stock of knowledge that people carry around in their heads as a result of living in particular cultures or subcultures' (Cunningham, 1993: 1). For Bourdieu, the habitus provides an understanding of how people respond appropriately, and often unconsciously, to different situations, events and interactions with other people.

Most significantly, habitus is the embodiment of these dispositions and practices. It provides a means of conceptualising that 'background understanding' (Taylor, 1999: 43) from which arise the often unthinking ways in which we react to things, as demonstrated in our bodily comportment - the way we stand, the way we look at others, the way we eat and so on. Thus, Butler (1999: 113-4) describes the habitus as the 'embodied rituals of everydayness', or in Bourdieu's (1990: 68) terms, 'body automatisms'. As the word automatism suggests, practices and rituals are spontaneous, and yet systematic. They are learnt over time, such that the habitus has a history. Taylor (1999: 42), for example, argues that children learn the 
meanings of culture, 'partly through inculcation of the appropriate habitus'. As he continues:

'We learn how to hold ourselves, how to defer to others, how to be a presence for others, all largely through taking on different styles of bodily comportment. Through these modes of deference and presentation, the subtlest nuances of social position, of the sources of prestige, and hence of what is valuable and good are encoded'.

Insofar as practices may be learnt, they are difficult to change and are passed on through generations. However, this raises questions about the effects of impairment on the habitus. For someone who suddenly becomes disabled, the learnt dispositions of the habitus may be ruptured. Practices may have to be learnt, or unlearnt in a conscious, thoughtful way. For disabled people, practices that are usually spontaneous may not be so thoughtless. Kuusisto (1998: 170-1) for example, notes the hours of practice and bodily re-orientation necessary when, after living for years with a visual impairment, he was given a guide dog. As he writes of moving around: “The street is more my own....I'm walking without the fight-or-flee gunslinger crouch that has been the lifelong measure of blindness... at age thirty-nine, I learn to walk upright".

Bodily dispositions, which are inculcated in people, are not themselves determined by the habitus, but by their interrelation with social fields. For Shilling (1993: 138), social fields are 'dynamic organising principles...which identify and structure particular categories of social practices (be they concerned with art, economics, eating, fashion...etc.)'. These fields ascribe values to certain social practices and forms of embodiment, and are, in a sense, the objective structures of Bourdieu's world. Thus, for disabled people, a dominant social field is medicine and the propagation of biomedical discourses which serve, as Foucault (1980: 54) 
notes, 'to ensure the physical vigour and moral cleanliness of the social body; it promised to eliminate defective individuals...it justified the racisms of the state...it grounded them in "truth"'. However, the relationship between the habitus and social fields is a mutually constitutive one. Fowler (1997: 23) notes the Giddensian (1991) parallels in Bourdieu's work: "people (agents), collectively or individually, transform or reproduce their social structures, but they do so within specific conditions, including those which are internalised as part of their habitus".

Thus, the bodily practices of the habitus, are produced by, but also produce and sustain, the social field. How then does a disabled person's habitus relate to different social fields, and how do these fields shape that "background understanding" which gives rise to embodied practices? As the bearer of dispositions, the body becomes inscribed with particular values related to the social field, inscriptions which, for Bourdieu (1990), may be defined by, and define, different social groupings, primarily, in his context, classes. As Bourdieu (1990: 172) suggests:

"inscribed within the dispositions of the habitus is the whole structure of the system of conditions, as it presents itself in the experience of a life-condition occupying a particular position within that structure. The most fundamental oppositions in the structure (high/low, rich/poor etc.) tend to establish themselves as the fundamental structuring principles of practices"

In this sense, the habitus, and its embodied practices, are implicated in social location and inequalities. Bourdieu (1990) notes how different values of practices become attached to the bodily comportment of men and women, and stresses how bodies become the site of physical capital, or bodies which are 'recognised as possessing value in social fields' (Shilling, 1993: 127). The acquisition of physical 
capital is also connected, in Bourdieu's (1990) terms, to the conversion of (bodily) status into other forms of capital, such as economic (e.g. the acquisition of money), cultural (e.g. the acquisition of education) and social (e.g. the development of social networks or contacts). In particular, dominant classes, because of their greater access to, and possession of, cultural and social capital, have the ability, as Bourdieu (1990) argues, to define their bodies and lifestyles as superior.

The habitus, then, is a source of symbolic value or the bodily and cognitive foundations underpinning the acquisition of prestige or status. However, the attainment of corporeal 'value', or bodily prestige or status, by disabled people is circumscribed by societal views which tend to define, and categorise, disabled people's bodies as 'abject' and abnormal, that is, bodies without value (Grosz, 1994, Hawkesworth, 2001). For disabled people, their bodies are usually understood, symbolically, only insofar as they deviate from a prescribed set of norms or where impairment is perceived as a threat and disabled people are "outsiders or symbolic 'others'." How, then, do social fields ascribe value to disabled people, and how do disabled people manage their bodies in seeking to acquire social and cultural capital? What do such processes reveal about the interrelationships between impairment and the social contexts underpinning the (re) production of disablement? These are themes to which we now turn.

\section{(3). Situating disability in bodies as bearers of value}

Bourdieu's sociology is concerned with the discovery of the socio-cultural processes underpinning the reproduction of structured inequalities. Likewise, as Shilling (1993: 127) suggests, the body, for Bourdieu, 'is an unfinished entity which develops in conjunction with various social forces and is integral to the 
maintenance of social inequalities'. Such inequalities are evidence of bodies as bearers of differential value or, as Joppke (1986: 60) notes, a 'reflection, acknowledgement and legitimation of a given distribution of economic, cultural, and social capital'. In adapting aspects of Bourdieu's ideas, we develop the proposition that the structured inequalities, characterising disabled people's lives, are related to processes in which dominant bodily forms 'monopolise not only physical capital but also political, symbolic and social capital, loosely

corresponding to and operationalised on different social field' (Gottfried, 1998: 459) (3).

In developing such ideas, the rest of the paper refers to the testimonies of people with a range of mobility, hard-of-hearing, and vision impairments. They were members of focus groups set up to document disabled people feelings and experiences of mobility and movement in the built environment (Imrie, 1999). Four focus groups were set up in England, two in Weymouth and two in Gateshead. The locations were chosen because of the willingness of local authority access officers to take part in the research, acting as gate-keepers in introducing the researchers to disabled people in their local communities. 30 disabled people volunteered to take part, all of who were recruited from the local population with the aid of the local access officers (see table 1). The sample was partial in a number of ways; for example, it was unintentionally weighted towards wheelchair users and people that one might characterise as politicised.

\section{Table 1 here}

Interviews also took place with property agents, such as developers and surveyors, and others, such as local authority officers, with an influence on the physical form of the built environment. The research explored a variety of themes, including: agents' attitudes towards, and understanding of, disabled people's 
access needs; disabled people's socialisation into particular patterns of bodily comportment and behaviour; their feelings about society's reactions and responses to their bodies; a documentation of the different ways in which disabled people respond to such reactions, and how they seek to influence them; and, a consideration of how broader, social and cultural, attitudes and practices interact with disabled people's impairments in (re) producing a diverse range of embodied experiences in the built environment.

Referring to the data, we discuss how interactions, between bodily impairments and broader socio-cultural relations, are implicated in the (re) production of structured inequalities based on corporeal signification and value. We develop the point made by Bordo (1993: 165), that the body 'is a powerful symbolic form, a surface on which the central rules, hierarchies, and even metaphysical commitments of a culture are inscribed and thus reinforced through the concrete language of the body'. We also discuss the contention that the systemic and structured inequalities of disability are (re) produced and reinforced by symbolic violence, or what Le Hir (2000: 135) refers to as 'a milder form of violence that cannot function without the complicity of the oppressed to their own oppression, but that remains invisible to them'.

\section{'Disminded bodily creatures' and the (de) valuation of disabled bodies}

Disadvantage and inequality of opportunity are the everyday experiences of disabled people (4). This is particularly apparent in relation to the labour market, and the physical capital vested in the disabled body. For Stone (1984: 90),

disability originated in the eyes of the state as an 'administrative category out of a collection of separate conditions understood to be legitimate reasons for not working'. Thus, disabled people are that other which defines who, and what, a 
normal worker is. For Oliver (1990), the de-valuation of the disabled body lies in the changing nature of labour under capitalism, which isolated disabled people, and brought their corporeal differences to the fore. The transformation of work from a 'rural based, co-operative system where individuals contributed what they could to the production process to an urban, factory-based one organised round the individual waged labourer' (Oliver, 1990: 27-8) de-valued the disabled body, and reduced its 'capacity to convert physical capital into other resources' (Shilling, 1993: 139).

Oliver's (1990) analysis points to one of the roots of the lack of symbolic power and status ascribed to the disabled persons body. The inability to work, and hence to gain value from the exchange of physical capital, is a feature of many disabled people's lives, marking them out as less than equal compared to their able-bodied counterparts. For instance, Britain's Disability Rights Task Force (1999: 35) notes that 'disabled people are only half as likely as non disabled people to be in employment' and 'there is no group of disabled people with an employment rate as high for non disabled people'. Some authors have documented disabled people's marginalisation from the labour market, and the social attitudes which abound about their embodied (dis) abilities (Doyle, 1995). Thus, as Hall (1999: 146) suggests, disabled people do not 'fit the image' sought after by employers, or that the presence of disabled people disrupts 'accepted notions of embodied employment'. Likewise, for Doyle (1995: 2) such situations 'are likely to be caused by employers stereotyping disabled persons and applying pre-conceptions about their abilities and employability'.

These attitudes reinforce biomedical conceptions of disability as reducible to (bodily) impairment, or as an interviewee, a manger of a property firm, commented: "nobody wants to be prejudiced against the disabled but there are certain things they cannot do. They can't fly planes, they can't go hang gliding, you've got to be 
realistic". Other employers echoed such sentiments with the director of a construction company commenting that "they (disabled people) can't do as much, we have to accept that". These statements de-value disabled people, and their bodily capabilities, as 'less than able', and reflect Bourdieu's (1990: 71) comment that 'the elementary acts of bodily gymnastics...are highly charged with social meaning and values'. However, as one respondent, a mobility impaired person, argued: "we are not invalid, invisible and certainly we are not stupid. It is the attitudes of managers of companies who do not want disabled people to work for them". Likewise, another disabled person noted that, "they (society) think they're looking after us but we want jobs and there's no reason that if we're given one we can't do it". The affirmation of a 'less than valuable' status is part of the daily routine of job applications and rejections for many disabled people. As one mobility impaired respondent stated:

"I've tried consistently since I broke my back to get work. Prior to breaking my back, I've never applied for a job without getting an interview... Since I broke my back I have never been asked for an interview, not once. $\mathrm{My} C V$ is impressive, and they take just one look at the fact that I broke my back and its finished"

The acquisition of a bodily impairment brought the sudden attribution of a body without value, and provides a stark illustration of how the body itself is implicated in reproducing inequalities (Shilling, 1993). This is particularly the case in a society where paid work is key to the acquisition of social status and citizenship rights. For some, however, rejection was more to do with the way in which social fields (re) produce social and environmental structures which devalue disabled bodies, or draw attention to the (functional) limitations of impairment. This is evident in relation to disabled people's mobility and movement in the built environment, or where inattentive design restricts disabled people's capacity to move from one place to another. As a respondent commented, "I've had lots of interviews for jobs but can't get one and I've given up...been going for 
telephonist and receptionist jobs but I've never been offered one because most of the businesses don't have accessible premises". Likewise, another wheelchair user stated:

"I can't work for solicitors in old office blocks, just can't get in. I've applied to schools and again they're problems with access. One school I applied to was for a temporary post and the reception window was too high so I couldn't see over it".

Disabled people's (lack of) acquisition of physical capital is, in part, related to biomedical discourses and the (social) field of medical, and related, practitioners. The medical profession has a powerful hold over what society deems to be the "legitimate body", and in Shilling's (1993: 145) terms, are one of a range of 'body experts' who define what constitutes an appropriate body in different social fields. As Bourdieu (1990: 69) notes, 'symbolic power works partly through the control of other people's bodies' and the medical professions' judgements affect "the recognition we have of our own body practices, and the body practices of others as 'right' and proper, or in need of control and correction" (Shilling, 1993: 145). Indeed, the respondent who broke her back noted how medical assessment had become a major part of applying for jobs since she acquired her impairment: "I've had 5 page documents to fill out asking me to list all the doctors appointments I've had in the last 5 years. What medication I've had, what the prognosis for the future is. Then you never hear back".

Such experiences bear witness to the role of medical models in influencing disabled people's struggles over corporeal identity, and 'what counts as a legitimate body' (Shilling, 1993: 145). Medical discourses are core to the definition of disabled people and incorporate values that stress the need to 'correct' or normalise the disabled body. Their dominance is such that most aspects of society are not generally structured in ways that provide frequent opportunities for value to be bestowed on disabled bodies. The body is constituted as an object to be 
tested for eligibility for state assistance and welfare support or, as a respondent said, 'what I get in benefits depends on what they (the medical assessors) think is wrong with me'. Such values seek to construct the body through an understanding of (bodily) function and appearance. At an extreme, 'welfare discourse reconstitutes impairment, poor health and age as self-inflicted dependencies' (Ellis, 1999: 43). Thus, as a mobility-impaired person commented about occupational therapists: "professionals don't know anything about us and I feel very angry...their criteria are a stupid joke. The way they treat us I feel like a poor crip after a while and I feel bad about myself".

The prominence of bio-medical ideas affects not only the potential physical capital vested in the disabled body, but also its cultural and symbolic value. As Branson and Miller (1991: 41) note, 'the contours of social inequality are structured through patterns of unequal access to symbolic capital, through unequal cultural competence...'. In this sense, disabled people are confined in their habitus through cultural impoverishment and cultural difference. In relation to cultural capital, for some disabled people their bodily demeanour is often interpreted negatively by others. Experiences of people avoiding or ignoring them is commonplace or, as a mobility impaired person recounted: "if you go to the supermarkets the older assistants just talk to the person beside you and often to my husband and not me". Similarly, another person noted: "people still walk at me, people don't see you as you don't get eye contact...I went to the TV shop with my father and the shop keeper spoke to my dad while I was the customer". In one sense, their responses reflect society's values - embodied in the habitus - about the way to respond to disabled people. Their embodied rituals reflect the demeaning valuations of disability (as impairment). As one respondent recounted: "try and get on a bus in with a walking stick. I was first in the queue and I just got pushed out of the way". 
Such bodily reactions to disabled people may often be unthinking, spontaneous, but at the same time, unconsciously learnt. An important part of the habitus is related to what Bourdieu (1977: 79) conceives of as behaviour related to the thoughtlessness of habit and habituation. In the context of disability, Hughes (1999: 165) refers to such behaviour as the 'perceptual pathology of nondisablement' or a condition which 'fails to recognise its own partiality'. Likewise, Paterson and Hughes (1999: 604) note that 'the information that animates the world is dominated by non disabled bodies, by a specific hegemonic form of carnality which excludes as it constructs'. These send out specific signals which favour the corporeal status of non-impaired people. As one respondent stated of a Shopmobility scheme, "initially, shopkeepers said we don't want the disabled to come in, there is still a perception that they get in the way, are poor and keep out the real customers". Similarly, another person noted that "the shops are all cluttered here...I've moved shoe boxes out of the way in at One Better in Boundary Street and received dirty looks, they just assume that their shop isn't for the disabled as they think we haven't got any money".

Such reactions also have implications for disabled people in the context of speech. As a respondent suggested "people don't know how to speak to disabled people...but people are more accepting of us now". Given the de-valuation of the disabled body, how are disabled people to speak with authority, or assert their views? Bourdieu refers to symbolic power to analyse the language use of dominated speakers or, as Bohman (1999: 137) notes, 'those whose speech lacks the legitimacy and authority to accomplish their goals and to acquire cultural advantage and wealth'. For instance, in meetings and forums that shape service-providing agencies, the ability to understand information and construct a coherent argument is seen as a necessity. However, for Flyvbjerg (1998: 228), such seemingly rational argument is often underpinned by modes of communication which serve to add validity, including 'eloquence' and 'charisma'. Disabled people unable to communicate in 
such a way, or draw on these rationalising modes, may find themselves disadvantaged in their ability to contribute to decision-making processes.

In developing such ideas, Paterson and Hughes (1999) refer to, after Leder (1990), 'dys-appearing bodies' or bodies, which because of their absence of 'normal' modes of movement, speech or verbal communication, are often mis-understood and ignored. Such bodies literally dys-appear and, as Paterson and Hughes (1999: 606) suggest, are 'annihilated as subject'. Thus, in seeking to communicate in a 'non-normal' form of speech, Paterson (in Paterson and Hughes, 1999: 606) describes the dys-appearance of his body, both functionally and aesthetically, when confronted with 'embodied norms of communication'. He recounts an experience of getting into a lift:

I was in a lift with a stranger when she began asking questions about university. It was an impossible situation because I realised that I would have no time no time to speak before one of us would reach our destination and have to exit the lift. The opportunity to communicate was constrained not only by the traveling time of the lift, but because the duration norm of this particular communication was not commensurate with my carnal needs...my options were reduced to a smile or a nod of the head, and I am reminded of my body. These every day codes of conduct (which favour the corporeal status of non-disabled people over my own) are in complicity with the oppression of disabled people'.

One of our respondents recalled similar events or, as she said: 'people look at me and treat me like a child and because I'm slow to talk no one ever has the patience to wait and listen...it's like I'm not there'. Such reactions reflect relations of domination which, in Bourdieu (1998: 29) terms, are most powerful when they are 'somatised, that is inscribed as active ingredient in the bodies - in the way people stand, walk, move, gesture - as well as in the minds that perceive them'. 
For disabled people, the denial of ascribed, and embodied, identity is common place, if only to deflect attention from the application of social stereotypes and preconceptions about their abilities. Thus, for one person, "everytime I go out I'm reminded of what I can't do and about what I'd like to do...and I just end up feeling bad (about myself)". For others, forms of bodily self censure, based upon embarrassment, awkwardness, or feelings of discomfort of perceived corporeal status, were evident. As a respondent noted, "normally when people ask I say 'no, I'm not disabled'. But I'm treated like a cripple. And always the inference is that if you've got a physical problem then obviously it means you have a mental one as well". For this person, their corporeality is akin to what Assister (1999: 82) characterises as 'disminded bodily creatures' or bodies without minds or mental capacities. Others felt likewise in conceiving of their bodies as inferior to their able-bodied counterparts, because of the ways in which social encounters reaffirmed their 'devalued selves'. For instance, in commenting on their body image, one respondent noted that "there are disabled people scared of going to able bodied places as they feel they can't compete".

However, for some disabled people, their way of life, and their bodily identity, becomes something that appears to be natural to them, or where the oppressive nature of the social world is hidden or not necessarily understood as influencing their bodily (de) valuations. This, then, is symbolic violence, or, as Bourdieu (1998: 12) suggests, 'a body knowledge that entices the dominated to contribute to their own domination by tacitly accepting, outside of any rational decision or decree of the will, the limits assigned to them'. For Bourdieu (1990: 128), 'symbolic violence is found...at the heart of each social relation' and in all institutions, and is reinforced by a process of mis-recognition. As Bourdieu (1977: 192) notes, "symbolic violence, the gentle, invisible form of violence, which is never recognised as such, and is not so much undergone as chosen". This, for Jenkins (1992: 104), is nothing less than the imposition of systems of symbolism and 
meaning upon groups or classes in such a way as they are experienced as legitimate'.

Symbolic violence tends to reproduce a medical understanding of disabled people, or where disabled people's bodies are labeled as deviant and disordered, requiring medical and charitable interventions. Thus, for one disabled person, their whole life had been a constant round of being cared for by organisations, or where their quality of life is subject to classifications used by occupational therapists. As she said: 'they lay down the criteria and assess my needs, but it's my body and I know what I need but you can't do much to challenge their decisions...you take what you're given'. Others concurred, with another person noting that their mobility was dependent on the local dial-a-ride bus service. However, as she suggested, 'it's nice to have it, but I can only go out when they're available and I have to fit in with them. There's no independence'. In both instances, disabled people were obligated to service providers and dependent on their rules and modes of domination which as Bourdieu says, is akin to a man who 'possesses in order to give. But he also possesses by giving'.

Likewise, for many disabled people, their dependence on going outside with a carer, or only being able to gain access to a building through a rear entrance, becomes a naturalised way of life, to which it is difficult to see alternatives, or openings for independence. For one person, "whenever I go out I just accept it as normal that I have to...use separate facilities...you do stand out though". Similarly, Kitchen and Law (2001: 296), in referring to the absence of wheelchair accessible toilets in Ireland, note that disabled people are often accepting of the situation in which the lack of toilets is 'naturalised and invisible to others'. The attitudes and responses of institutions and other people in society only reinforce the 'naturalness' and ordinariness of such situations (5). As one respondent noted of the local council's attitude to providing for wheelchair users, "it is taken for granted 
that a person in a wheelchair won't come out on their own, they're always seen as a person who will be pushed".

For Bourdieu (2000: 169), such experiences are 'exercised invisibly and insidiously through familiarisation with a symbolically structured physical world...informed by the structures of domination'. Thus, as a wheelchair user noted, 'wherever I go there are obstructions, barriers, things that get in the way; it makes it difficult to move about. People with legs are $O K$ and so nothing will ever change'. For others, it was normal to be given the 'back-door' treatment when seeking to enter a building. Thus, for another wheelchair user, 'back door quality all the time! We go through side doors, back doors, back alleys, everywhere but the front; it's degrading but we all accept it'. The impaired carnality of disabled people was highlighted as requiring different, yet unequal, treatment to the 'normal' body. As one respondent commented:

"I think even though we've got more choices, there's still limits. If you want to go to a venue with more than one wheelchair user, you've got limits. If you want to go to the pictures and you want to go with a group, two will have to sit over there, another two over there. You don't have to do that if you're non-disabled. Disabled people are always expected to be separated'.

Likewise, a mobility-impaired person commented that: "you can guarantee that if you go somewhere with friends, it's not accessible for you. You actually rely on your friends to get you around, even though I am independent. In this environment, I'm independent, if you put me in another environment, I'm not". Others conveyed feelings of 'not being wanted' or being made to feel unwelcome by the spatial or physical arrangements of particular places. As a hearing-impaired person said, about her deaf association attending a meeting: "The first thing that hit us was that one of the attendees was hearing impaired and to get into the building you had to press a button and then somebody says 'who are you?' and if you can't hear how can you respond?" Others 
recounted similar experiences, or where their (bodily) subjectivities were a target for what respondents perceived to be unfair and discriminatory treatment. Thus, for a wheelchair user. the "last time I travelled on the train I had to travel in the parcel van, but I still had to pay the full fare. Do I look like a parcel".

This person's objectified identity is illustrative of how culture is encoded in or on the body or, as Jenkins (1992: 179) suggests 'the power of habituation derives from the role of the body both as a mnemonic device in cultural coding and as an effective vehicle for the less-than-conscious communication or expression of those codes'. Thus, from the aesthetic expressions of disabled people without muscular control, to the powerful signification of the wheelchair (e.g. 'the parcel'), the cultural encoding of disability is one which often renders the disabled body as broken, incompetent, powerless, and dependent (or a body without a subjectivity). However, such descriptions, as Bourdieu (1990) notes, are neither fixed nor unchanging, but reflect the context-specific interrelationships between bodily expression and social structure and agency.

\section{(4). Conclusions}

Disabled people's bodies are subjected to the values of a society that renders them 'less than valuable' and inferior to those considered to be the embodiment of 'normality'. From genetic testing to identify those to be aborted before birth, to the social and cultural signification of the habitus, disabled people's experiences reinforce their marginality and inferior status in society. An understanding of such marginality is, however, hindered by disability theory which is riven by divisions and differences. In particular, dominant discourses of disability reproduce dualistic conceptions of disability. Thus, disability is characterised either as a product of a biological deficiency or as the result of socially constructed forms of 
disadvantage. Bourdieu's sociology is important because it seeks to circumvent such dualistic conceptions of theory and practice or, as he suggests, 'to act is to act with a structured body which has incorporated the immanent structures of a world or of a particular sector of that world - a field - and which structures the perceptions of that world as well as action in that world' (Bourdieu, 1998: 81).

The importance of Bourdieu's sociology, for the development of disability theory, is more than just the transcendence of mind/body or society/nature dualisms. Thus, for Bourdieu, social location and inequalities are understood, in part, in relation to bodily dispositions (i.e. to comportment, ways of talking, eating, sitting, touching, etc) and to bodies as bearers of value. This focus is important because it highlights the embodied nature of disability as an analytical category of inquiry, while serving to redress, potentially, discourses of disability which remain disembodied. As Bourdieu says (1990: 23), 'the habitus, as society written into the body, into the biological individual'. Such insights contribute to the calls by scholars, such as Zola (1991: 1), to bring 'bodies back in', or to recognise how corporeal practices 'produce and give a body its place in everyday life' (Turner, 2001: 259). Bourdieu's sociology, we would suggest, is one small contribution to this broader endeavour.

\section{Acknowledgements}

Our thanks to the referees whose perceptive comments permitted us to improve the paper, and also to the Economic and Social Research Council (grants R000235833 and R00429734443) who funded the research. 


\section{Footnotes}

(1). It is our belief that issues about social justice are core to the lives of disabled people, and that academic research ought to be clearly connected to overturning the inequities of disablism. Such inequities consign disabled people to low levels of educational attainment and to unemployment or, at best, the lower rungs of the labour market. As a consequence, material deprivation and poverty are features of disabled people's lives. Our paper seeks to highlight how bodily (de) valuations are, in part, linked to social inequalities. It does so in order to contribute to the work of disabled people's groups who call for policy committed research or research that promotes citizenship rights, equal opportunities and inclusion.

(2) The dominant strands of disability theory are infused with sociological and philosophical dualisms. Thus, the social model conforms with what Bouverserse (1999: 47) refers to as 'a system of objective relations that transcend individual agents', whereas the medical model adopts a subjectivist position or one which elevates individual pathologies and actions to a determinate level (of understanding).

(3). There are, however, limitations to Bourdieu in developing an understanding of how people's corporeality shapes their lives. Whilst seeking to overcome the dualisms of biological or societal explanation of social life, Bourdieu has, as Shilling (1993: 148) notes, an 'underdeveloped view of the biological dimensions of human embodiment'. Disabled people's impairments may prevent them from adopting spontaneous and unconscious dispositions usually associated with the habitus. They may not move, speak, or react in the same way that others do.

(4). However, this is not to suggest that disabled people constitute a homogeneous, coherent, and stable group; far from it, or, as Barnes, et al (1999: 14) note, 'disability does not have a universal character' and disabled people do not easily fit into any coherent category (of explanation or experience).

(5). This 'naturalness' is, however, a product of the social world. To think otherwise might well lead to a problematical analysis of disabled people which 'blames them' for their social status and position. 

Table 1: Characteristics of the focus groups

\begin{tabular}{|c|c|c|c|}
\hline $\begin{array}{c}\text { Group } 1 \\
\text { Weymouth }\end{array}$ & $\begin{array}{c}\text { Group } 2 \\
\text { Weymouth }\end{array}$ & $\begin{array}{c}\text { Group } 3 \\
\text { Gateshead }\end{array}$ & $\begin{array}{c}\text { Group } 4 \\
\text { Gateshead }\end{array}$ \\
\hline $\begin{array}{l}9 \text { participants; } \\
44 \text { male } \\
\text { and } 5 \text { female }\end{array}$ & $\begin{array}{c}5 \text { respondents: } \\
\qquad 4 \text { male } \\
\text { and } 1 \text { female }\end{array}$ & $\begin{array}{c}8 \text { respondents: } \\
4 \text { male } \\
\text { and } 4 \text { female }\end{array}$ & $\begin{array}{c}8 \text { respondents: } \\
4 \text { male } \\
\text { and } 4 \text { female }\end{array}$ \\
\hline $\begin{array}{c}2 \text { in } \\
\text { wheelchairs }\end{array}$ & $\begin{array}{c}3 \text { in } \\
\text { wheelchairs }\end{array}$ & $\begin{array}{c}4 \text { in } \\
\text { wheelchairs }\end{array}$ & $\begin{array}{l}3 \text { in } \\
\text { wheelchairs }\end{array}$ \\
\hline $\begin{array}{l}3 \text { visually } \\
\text { impaired }\end{array}$ & $\begin{array}{l}1 \text { with speech } \\
\text { impairment }\end{array}$ & $\begin{array}{l}1 \text { visually } \\
\text { impaired }\end{array}$ & $\begin{array}{l}3 \text { visually } \\
\text { impaired }\end{array}$ \\
\hline $\begin{array}{l}2 \text { hearing } \\
\text { impaired }\end{array}$ & $\begin{array}{c}1 \text { with walking } \\
\text { difficulties }\end{array}$ & $\begin{array}{l}1 \text { hearing } \\
\text { impaired }\end{array}$ & $\begin{array}{l}3 \text { hearing } \\
\text { impaired }\end{array}$ \\
\hline $\begin{array}{c}2 \text { with walking } \\
\text { difficulties }\end{array}$ & & $\begin{array}{l}2 \text { with } \\
\text { difficulty in } \\
\text { walking }\end{array}$ & \\
\hline
\end{tabular}




\section{References}

Assister, A., 1999, Bodies and Dualism, in Ellis, K. and Dean, H., (eds.), Social policy and the body: transitions in corporeal discourse, MacMillan Press, London, 63-82.

Barnes, C., Mercer, G., and Shakespeare, T., 1999, Exploring disability: a sociological introduction, Polity, Oxford.

Bohman, J., 1999, Practical reason and cultural constraint: agency in Bourdieu's theory of practice, in Shusterman, R., (ed), Bourdieu: a critical reader, Blackwell, Oxford, 129-152.

Bordo, S., 1993, Unbearable weight: feminism, western culture, and the body, University of California Press, Berkeley.

Bourdieu, P., 1977, Outline of a theory of Practice, Cambridge University Press, Cambridge.

Bourdieu, P., 1985, The social space and the genesis of groups, Theory and Society, 14, 723-744.

Bourdieu, P., 1990, The Logic of Practice, Polity, Oxford.

Bourdieu, P., 1998, La domination masculine, Ed. du Seuil, Paris.

Bourdieu, P., 2000, Pascalian Meditations, Polity, Oxford.

Bouveresse, J., 1999, Rules, dispositions, and the habitus, in Shusterman, R., (ed.), Bourdieu: A Critical Reader, Blackwell, Oxford, 45-63.

Branson, J. and Miller, D., 1991, Pierre Bourdieu, in Beilharz, P. (ed.), Social Theory: a guide to central thinkers, Allen and Unwin, London.

Butler, J., 1999, Performativity's Social Magic, in Shusterman, R., (ed.), Bourdieu: A Critical Reader, Blackwell, Oxford, 113-128

Cunningham, J., 1993, Habitus and misrecognition, unpublished paper available from the author, Ontario Institute for Studies in Education, Toronto, Canada.

Disability Rights Task Force, 1999, From Exclusion to Inclusion, final report of the DRTF, Department of Education and Employment, London. 
Douglas, M., 1966, Purity and danger: an analysis of the concepts of pollution and Taboo, Routledge and Kegan Paul, London.

Doyle, B., 1995, Disability, discrimination and equal opportunities: a comparative study of the employment rights of disabled persons, Mansell, London.

Elias, N., 1991, The Symbol Theory, Sage, London.

Ellis, K., 1999, The care of the body, in Ellis, K. and Dean, H., (eds.), Social Policy and the Body: Transitions in Corporeal Discourse, MacMillan, London, 23-44.

Flyvbjerg, B., 1998, Rationality and Power, Chicago University Press, Chicago. Foucault, M., 1980, Power/Knowledge, Pantheon, New York.

Fowler, B., 1997, Pierre Bourdieu and Cultural theory: Critical Investigations, Sage, London

Giddens, A., 1991, Modernity and Self Identity, Polity, Cambridge.

Gottfried, H., 1998, Beyond patriarchy? Theorising gender and class, Sociology, $32,451-468$.

Grosz, E., 1994, Volatile bodies: towards a corporeal feminism, Indiana University Press, Bloomington.

Hall, E., 1999, Workspaces: refiguring the disability-employment debate, in Butler, R. and Parr, H., (eds.), Mind and body spaces: geographies of illness, impairment and disability, Routledge, London, 138-154.

Hawkesworth, M., 2001, Disabling spatialities and the regulation of a visible secret, Urban Studies, 38, 2, 299-318.

Hughes, B., 1999, The constitution of impairment: modernity and the aesthetic of oppression, Disability and Society, 14, 2, 155-172.

Imrie, R., 1999, The role of access groups in facilitating accessible environments for disabled people, Disability and Society, 14, 4, 463-482.

Jenkins, R., 1992, Pierre Bourdieu, Routledge, London. 
Joppke, C., 1986, The cultural dimensions of class formation and class struggle: on the social theory of Pierre Bourdieu, Berkeley Journal of Sociology, 31, 51-78.

Kitchen, R. and Law, R., 2001, The socio-spatial construction of (in) accessible public toilets, Urban Studies, 38, 2, 287-298.

Kuusisto, S., 1998, Planet of the Blind, Faber and Faber, London.

Leder, D., 1990, The Absent Body, Chicago University Press, Chicago.

Le Hir, M., 2000, Cultural studies Bourdieu's way: women, leadership, and feminist theory, in Brown, N. and Szeman, I., (eds.), Pierre Bourdieu: Fieldwork in Culture, Rowman and Littlefield, New York, 123-144.

Marks, D., 1999, Disability: controversial debates and psychosocial perspectives, Routledge, London.

Meekosha, H., 1998, Body battles: bodies, gender and disability, in Shakespeare, T., (ed.), The Disability Reader: social science perspectives, Cassell, London, 163180.

Merleau-Ponty, M., 1962, The Phenomenology of Perception, Routledge and Kegan Paul, London.

Morris, J., 1991, Pride against Prejudice, The Women's Press, London.

Oliver, M., 1990, The Politics of Disablement, MacMillan, London.

Oliver, M., 1996, Understanding disability: from theory to practice, MacMillan, London.

Painter, J., 2000, Pierre Bourdieu, in Crang, M. and Thrift, N., (eds.), Thinking Space, Routledge, London, 239-259.

Paterson, K. and Hughes, B., 1999, Disability studies and phenomenology: the carnal politics of everyday life, Disability and Society, 14, 5, 597-611.

Shilling, C., 1993, The Body and Social Theory, Sage, London.

Stone, D., 1984, The Disabled State, MacMillan, London.

Taylor, C. 1999, To follow a rule, in Shusterman, R. (ed.), Bourdieu: A Critical Reader, Blackwell, Oxford, 29-44 
Turner, B., 1992, Regulating bodies: essays in medical sociology, Routledge, London.

Turner, B., 2001, Disability and the sociology of the body, in Albrecht, G., Seelman, K., and Bury, M., (eds.), Handbook of Disability Studies, Sage, London, 252-266.

Zola, I., 1991, Bringing our bodies back in: reflections on a past, present, and future medical sociology, Journal of Health and Social Behaviour, 32, 1, 1-16.

Biographical note: Claire Edwards is Research Officer at the Department of Work and Pensions. Rob Imrie is Professor of Human Geography in the Department of Geography at Royal Holloway University of London and is co-author (with Peter Hall) of Inclusive Design (Spon Press, 2001) and author of Disability and the City (Paul Chapman Publishing, London). 